九州大学学術情報リポジトリ

Kyushu University Institutional Repository

\title{
Activity of alumina-silica-supported NiMoS prepared by controlled mixing of alumina into Si0_2 hydrogels for HDS of gas oil
}

Nakano, Koj i

Catalyst Research Center, JGC Catalysts and Chemicals Ltd.

Pang, We iwe i

Institute for Materials Chemistry and Engineering, Kyushu University

Lee, Jihn-Koo

Institute for Materials Chemistry and Engineering, Kyushu University

Park, Joo-Il

Institute for Materials Chemistry and Engineering, Kyushu University

他

http://hdl. hand le. net/2324/25484

出版情報：Fuel Processing Technology. 92 (5)，pp. 1012-1018，2011-05-05. Elsevier バージョン :

権利関係: (C) 2011 Elsevier B.V. 


\title{
Activity of alumina-silica-supported NiMoS prepared by controlled mixing of alumina into $\mathrm{SiO}_{2}$ hydrogels for $\mathrm{HDS}$ of gas oil
}

\author{
Koji Nakano ${ }^{a}$,Weiwei Pang ${ }^{\mathrm{b}}$, Jihn-Koo Lee ${ }^{\mathrm{b}}$, Joo-Il Park ${ }^{\mathrm{b}}$, Seong-Ho, Yoon ${ }^{\mathrm{b}, *}$, and Isao \\ Mochida $^{\mathbf{b}}$ \\ ${ }^{a}$ Catalyst Research Center, JGC Catalysts and Chemicals Ltd., Kitakyushu, Fukuoka, Japan \\ ${ }^{b}$ Institute for Materials Chemistry and Engineering, Kyushu University, Kasuga, Fukuoka, Japan \\ * Corresponding author: Tel: +8192583 7959; Fax: +81925837897 \\ E-mail address: yoon@asem.kyushu-u.ac.jp
}

\begin{abstract}
Alumina-silica-supported NiMoS composites were examined in single- and dual-layer catalyst beds in a high-pressure (5 MPa) flow reactor to achieve ultra low sulfur $(10 \mathrm{ppm})$ diesel fuels. Three types of alumina-silica composite supports were prepared by co-precipitation to control the particle size and arrangement of alumina and silica. $\mathrm{SiO}_{2}$ content influenced the catalytic performance, and the maximum conversion was $\sim 27 \%$, regardless of the preparation conditions. Alumina crystal size controlled the acidity and surface area of the support, key factors influencing catalytic performance. NiMoASA-2(27), prepared by procedure 2, achieved 4.5 and $3 \mathrm{ppm} \mathrm{S}$ at 345 and $360^{\circ} \mathrm{C}$, respectively, in the single bed reactor at a liquid hourly space velocity (LHSV) of $1 \mathrm{~h}^{-1}$. NiMoASA-2(27) achieved the best performance of the supports examined in this study. The double-layer catalyst bed contained commercial CoMoS (LX6) and NiMoASA-2(27) in the first and the second beds at 345 and $360^{\circ} \mathrm{C}$, respectively, and achieved 5 and 2 ppm $\mathrm{S}$, indicating better performance at higher temperatures. The reaction order for the hydrodesulfurization (HDS) of refractory sulfur species was close to unity over NiMoASA-2(27), which was significantly higher
\end{abstract}


than that of the commercial CoMoS catalyst. Alumina-silica-supported NiMoS in the second bed of the dual-layer catalyst bed achieved less than $10 \mathrm{ppm} \mathrm{S}$ for refractory sulfur species with $\sim 500 \mathrm{ppm} \mathrm{S}$.

Key words: alumina-silica, preparation, particle size, $\mathrm{SiO}_{2}$ content, activity

\section{Introduction}

Deep hydrodesulfurization (HDS) of gas oil is required to meet environmental regulations worldwide [1]. To achieve less than $10 \mathrm{ppm} \mathrm{S}$ in gas oil, catalysts and processes have been studied using existing HDS reactors. New developments must operate under $\mathrm{H}_{2}$ pressure and liquid hourly space velocity (LHSV) comparable to these reactors.

Deep HDS of refractory sulfur-containing species, such as 4,6-dimethyldibenzothiophene (4,6-DMDBT), and rapid HDS of reactive sulfur species are challenges of deep HDS [2, 3]. Rapid HDS of reactive species allows longer reaction times for deep HDS of refractory sulfur species, which tends to be slow. The most effective catalyst for these two issues is not always the same; thus, double-layer beds of two optimum catalysts have been used for rapid HDS of reactive sulfur species and deep HDS of refractory sulfur species within commercially reported reaction times and temperatures [4]. These issues have been solved by hydrogenation of one phenyl group in alkyl-DBTs or shifting the methyl groups at the 4 and 6 positions before deep HDS [5, 6]. Acidic supports, combined with NiMoS, can enhance such prereactions for deep HDS $[7,8]$ and improve the resistance of the catalyst to $\mathrm{H}_{2} \mathrm{~S}[9,10]$, which tends to be more concentrated in the second than in the first layer.

Numerous binary oxides, such as alumina-silica, -boria, -phosphate, and-zeolite, have been reported to enhance HDS of refractory sulfur species [4, 9]. For acidic enhancement of HDS catalysts, excess cracking of gas oil and strong inhibition of basic poisons are concerns, even if $\mathrm{H}_{2} \mathrm{~S}$ inhibition is markedly reduced by the acidic support [11]. Thus, the acidity of the supports must be controlled carefully. Additionally, the hydrogenation activity of a catalyst is strongly governed by the dispersion or supported form of NiMoS [12, 
13]. The support must allow adequate dispersion of NiMoS by providing more active sites for $\mathrm{MoS}_{2}$ coordination. The binary oxides of the acidic support must be designed to provide high catalytic activity for deep HDS $[14,15]$.

In this paper, we propose a series of alumina-silica supports for deep HDS. Silica addition to alumina was the first option used to optimize the acidity and the supporting sites of the binary oxides $[4,16]$. The optimum silica content was 20-30 wt $\%$, much lower than that reported for acidic catalysts. Alumina and silica particle size and arrangement must be optimized to provide higher acidity and increased support sites, simultaneously [17].

In the present study, HDS activities of NiMoS supported on three types of alumina-silica supports prepared using co-precipitation of silica were investigated over single- and dual-layer catalyst beds in a flow reactor to examine their performances under commercial test conditions. The catalyst of the first stage was fixed as a commercial CoMo catalyst (LX6) that can desulfurize gas oil to less than 500 ppm S. The three types of alumina-silica supports have different arrangements of alumina and silica nanoparticles. Kinetic performance was estimated to identify activity-structure correlations in the HDS catalysts and to optimize the reaction design for efficient deep HDS of gas oil.

\section{Experimental}

\subsection{Catalysts}

Amorphous alumina-silica supports (ASA) were prepared by co-precipitation of alumina and silica sources in water. Three ASA supports (ASA-1, ASA-2, and ASA-3) were prepared by procedure 1, 2, and 3, respectively. For procedure 1, alumina oxide source A was introduced into the $\mathrm{SiO}_{2}$ hydrogel, and then alumina oxide source $\mathrm{B}$ was added to form an $\mathrm{Al}_{2} \mathrm{O}_{3}-\mathrm{SiO}_{2}$ slurry. For procedure 2, the $\mathrm{SiO}_{2}$ hydrogel was introduced into alumina oxide source B, and then alumina oxide source A was added. For procedure 3, the $\mathrm{Al}_{2} \mathrm{O}_{3}$ hydrogel prepared by two different alumina oxide sources, $\mathrm{A}$ and $\mathrm{B}$, was introduced into the $\mathrm{SiO}_{2}$ 
hydrogel. These ASA precursors were shaped to 1.6-mm diameter pellets by extrusion and calcined. The silicon oxide content in the catalyst carrier was $28 \%$ for ASA-1 and $24 \%$ for ASA-3. ASA-2 carried various silica contents, including $7 \%, 12 \%, 27 \%, 50 \%$ and $70 \%$, with controlled preparation conditions using procedure 2. The ASA-2 supports are abbreviated as ASA-2(n) $(\mathrm{n}=$ silica content). In particular, ASA-2(27) is referred to as ASA-2 for comparison with ASA-1 and ASA-3. For comparison, an alumina support (A) was also prepared by precipitation with an alumina source alone. Active metals molybdenum and nickel were co-impregnated by the pore-filling method. The impregnated catalyst precursor was dried and calcined to produce an oxide form of the binary active metals. The amount of active metals in all catalysts was carefully controlled to $5 \mathrm{wt} \%$ nickel oxide and $20 \mathrm{wt} \%$ molybdenum oxide (referred to as NMASA-1, NMASA-2(n), and NMASA-3), respectively.

\subsection{Catalyst Characterization}

Specific surface areas and pore volumes of carrier oxides were analyzed by the nitrogen BET method (BELSORP-Max-S, BEL Japan). Their surface areas and pore size distributions are summarized in Table 1 and Figure 1, respectively. ASA supports showed surface areas of $303-335 \mathrm{~m}^{2} / \mathrm{g}$, average pore sizes of 2.1$3.1 \mathrm{~nm}$, and pore volumes of $0.58-0.70 \mathrm{~cm}^{3} / \mathrm{g}$. ASA-2 showed the highest surface area, highest pore volume, and mid-range pore size compared to ASA-1 and ASA-3.

$\mathrm{NH}_{3}$-temperature-programmed desorption (TPD) of the oxide form of the catalysts was carried out to measure total acidity using a TPD-I-AT (Nippon Bell Co.) equipped with a quadruple mass spectrometer (QMS) gas analyzer. The acidities of NMASA-1 and -3 were 0.35 and $0.56 \mathrm{mmol} \mathrm{NH}_{3} / \mathrm{g}$ catalyst, respectively. The acidities of NMASA-2 with 7\%, 12\%, 27\%, 50\%, and 70\% silica content were estimated to be $0.61,0.64,0.82,0.67$, and $0.63 \mathrm{mmol} \mathrm{NH}_{3} / \mathrm{g}$ catalyst, respectively [4].

The structures of the three ASA supports were examined using high-resolution transmission electron microscopy (HR-TEM; JEM-2100F, JEOL). Figure 2 shows TEM images of ASA1-28, ASA2-27, and ASA3-24. 


\subsection{Hydrodesulfurization}

HDS activities of the catalysts were investigated using a high-pressure flow-type reactor catalyst test unit. The unit consisted of two fixed-bed reactors in series, a pressure controller, a high-pressure oil pump, a mass flow controller to adjust gas flow, and a separator for liquid and gas products. Hydrogen gas and feed oil were supplied from the top of the reactor to the bottom. The unit was capable of operating under high-pressure conditions. Each reactor had a separate thermocouple for temperature control. The gas supplied to the unit was $90 \mathrm{vol} \% \mathrm{H}_{2} / 10 \mathrm{vol} \% \mathrm{~N}_{2}$ mixed gas. Standard reaction conditions are summarized in Table 2.

Two types of straight-run gas oil (SRGO), 1 and 2, were used as feed oils, and their properties are summarized in Table 2. SRGO2 was used as the feed oil for all tests except for the study of the effect of silica content on catalytic performance for NMASA-2 in the second catalyst layer bed. The catalyst was presulfided at $330^{\circ} \mathrm{C}$ for $2 \mathrm{~h}$ under a stream of $3 \mathrm{vol} \% \mathrm{H}_{2} \mathrm{~S} / \mathrm{H}_{2}$ mixed gases prior to HDS. The activity of the catalyst was evaluated at reaction temperatures of 330,345 , and $360^{\circ} \mathrm{C}$ at a LHSV of $1 \mathrm{~h}^{-1}$. The LHSV was varied from 0.5 to $2.0 \mathrm{~h}^{-1}$ for the kinetic study. The partial $\mathrm{H}_{2}$ pressure was varied from 2.5 to $7.5 \mathrm{MPa}$ to measure the effects of $\mathrm{H}_{2}$ pressure. The catalysts were aged prior to product sample collection at each reaction temperature.

Commercial LX6 was loaded into the first reactor at $50 \mathrm{vol} \%$ of the total catalyst volume, and the prepared NMASA catalyst was loaded into the second reactor at the remaining 50 vol\% to test the duallayer catalyst system. Both reactors were filled with the same catalyst for the single-layer catalyst system.

The densities of the HDS oils were analyzed using a density meter (DA-500, Kyoto-Densi), sulfur content was analyzed by X-ray fluorescence spectroscopy (MDX-1058, Oxford), nitrogen (TS-100V, Mitsubishi Chemicals) and aromatic content (1A, 2A, 3A+) were analyzed by gas chromatography (GC353B-FID GL Science, equipped with a super critical $\mathrm{CO}_{2}$ carrier and FID detector), and distillation properties were analyzed according to ASTM D-86. The yields of the hydro-treated oils were calculated to 
be $\sim 98 \%$.

The sulfur and nitrogen species in the feed and their hydrodesulfurized products were analyzed at the molecular level with a gas chromatograph (HP6890+, Agilent) equipped with an atomic emission detector (G2350A, JAS, GC-AED). Detailed conditions for these analyses have been described previously [18].

\section{Results and Discussion}

\subsection{Catalytic performance of NMASA-1, -2, and -3 in single- and dual-layer catalyst beds}

Figure 3 shows HDS activities for NMASA-1, -2 , and -3 and for reference catalysts LX6 and NMA in the single-layer catalyst bed. Among the NMASAs, NMASA-2 showed the best performance, achieving 4.5 and $3 \mathrm{ppm} \mathrm{S}$ at 345 and $360^{\circ} \mathrm{C}$, respectively, NMASA-3 achieved 9 and $3 \mathrm{ppm}$ at 345 and $360^{\circ} \mathrm{C}$, respectively, and NMASA-1 was inferior to the other two catalysts, achieving $230 \mathrm{ppm} \mathrm{S}$ under the same conditions. NMASA-1 and NMASA-3 catalysts showed a limited increase in their activities at $360^{\circ} \mathrm{C}$, probably due to a limited increase in hydrogenation activity at this temperature under fixed $\mathrm{H}_{2}$ pressure. The performances of two reference catalysts, LX6 and NMA, were compared with those of NMASA-2 and -3 . The reference catalysts achieved sulfur levels below $10 \mathrm{ppm}$ at $360^{\circ} \mathrm{C}$, although $\mathrm{LX} 6$ has been reported to be an excellent HDS catalyst capable of achieving 50 ppm S under commercial conditions. Product analysis showed that LX6 removed all reactive sulfur species very efficiently.

Figure 4 shows HDS activities for the dual-layer catalyst bed in which the first layer catalyst was LX6 in all cases and the second layer catalyst was varied. The combination of LX6 and NMASA-2 showed much higher activity than the four other combinations, achieving 6.6 and $2 \mathrm{ppm} \mathrm{S}$ at 345 and $360^{\circ} \mathrm{C}$, respectively. Figure 4 suggests that half the NMASA-2 could be replaced by LX6 to achieve far less than $10 \mathrm{ppm} \mathrm{S}$ at both 345 and $360^{\circ} \mathrm{C}$. Such activities are favorable for stability of the catalysts because inevitable deactivation towards the end of a run requires higher reaction temperatures to compensate for activity loss $[19,20]$. LX6 and NMASA-2 shared their respective roles for rapid HDS of reactive and 
refractory sulfur species, respectively.

Among ASAs with similar silica content, of 24-28\%, ASA2-27 was the best support for the secondlayer catalyst. ASA3-24 was slightly inferior to ASA2-27 for HDS performance. ASA1-28 was inferior to both ASA2-27 and ASA3-24. The major difference between these supports was their alumina crystal size, in the order ASA $1>$ ASA $2>$ ASA 3. Thus, the largest alumina crystal size corresponded to the worst performance, and the intermediate size was better than the smallest size. Details on achieving these activities will be discussed below.

HDS levels achieved by the single catalyst bed of NMASA-2(27) and the dual-layer catalyst bed were similar in the short term at $345^{\circ} \mathrm{C}$. All catalyst combinations in the dual-layer bed achieved less than $10 \mathrm{ppm} \mathrm{S}$ at $360^{\circ} \mathrm{C}$. At the lower reaction temperature, $345^{\circ} \mathrm{C}$, the combination of LX6 and NMASA-2 was expected to achieve less than $10 \mathrm{ppm} \mathrm{S}$ because LX6 alone and the other four combinations failed to reach this target.

Figure 5 shows GC-AED spectra of HDS products for the dual-layer bed with four catalyst combinations at $345^{\circ} \mathrm{C}$. Their activities differed due to the remaining refractory sulfur species almost exclusively, especially 4,6-DMDBT and TMDBT. The LX6/NMASA-2 combination removed almost all refractory sulfur species under the present conditions.

LX6 has been used for HDS to achieve less the $500 \mathrm{ppm}$ S diesel fuel by rapid HDS of reactive sulfur species, although its activity for refractory sulfur species was not sufficient for deep HDS because of limited hydrogenative HDS of refractory sulfur species. The product of the first layer bed had almost no reactive species. Thus, the reaction of the second catalyst bed was exclusively HDS of refractory sulfur species, despite the fact that $\mathrm{H}_{2} \mathrm{~S}$ from the major reactive sulfur species moved to the second layer and increased $\mathrm{H}_{2} \mathrm{~S}$ concentrations. In contrast, NMASA-2(27) was very active for refractory sulfur species due to its excellent hydrogenation activity on the neighboring phenyl group in the hindered dibenzothiophene rings under high $\mathrm{H}_{2} \mathrm{~S}$ concentrations. 
Figure 6 shows distillation profiles of HDS oils over a dual-layer catalyst bed at $345^{\circ} \mathrm{C}$. The profiles were very similar except that the products over LX6/NMASA-1 had slightly higher initial distillation temperatures. The extent of cracking over the catalysts was similar. NMASA-2(27) in the second layer catalyst bed promoted cracking to produce fractions lighter than that of diesel for a similar yield of ultra low sulfur diesel product (10 ppm S). The refractory sulfur species were almost completely removed at $345^{\circ} \mathrm{C}$

The stability of the catalyst and product distillation profiles improved due to reactions in the dual-layer catalyst bed with CoMoS in the first layer. The feed treatment in the first layer bed (LX6) with lower acidity may have reduced the coking load in the second layer. Hydrogen consumption and coking extent were controlled by the amount of catalyst in the second layer because such reactions were affected by the acidity of the catalyst, with less NMASA-2(27) preferred for deep HDS.

Figure 7 shows the densities of product oils. LX6/NMASA-2 resulted in much lower density of the product oil, improving the value of the product. The higher reaction temperature of $360^{\circ} \mathrm{C}$ reduced the density of the products significantly, regardless of catalyst combinations.

Figure 8 shows carbon GC-AED spectra of the products over the four catalyst combinations. The spectra were very similar except that more product eluted in a shorter time range over LX6/NMASA-1. This result is consistent with the product distillation profiles.

Figure 9 shows total aromatic and polyaromatic contents in the product oils. LX6/NMASA-2 achieved the lowest total aromatic and polyaromatic content in the product. The highest hydrogenation of aromatic compounds occurred in the reaction over LX6/NMASA-2, resulting in the lowest densities of the products.

Density, total aromatic content, and polyaromatic content were significantly reduced by the dual-layer catalyst bed. The second layer of NMASA-2(27) promoted effective hydrogenation, leading to deep HDS, lower density, and reduced aromatic content. 
Figure 10 shows sulfur contents of HDS oils over NMASA-2 with various silica contents in the second bed of the dual-layer catalyst system with LX6 in the first bed. HDS activity was affected by silica content in NMASA-2 and was optimized at $27 \%$ silica. HDS activity was markedly reduced by increasing or decreasing the silica content from $27 \%$.

Figure 11 shows GC-AED spectra of HDS products on LX6/NMASA2 series catalysts. Refractory sulfur compounds, such as 4,6-DMDBT and TMDBT, remained in the product oil except over NMASA-2(12) and NMASA-2(27). Two $\mathrm{SiO}_{2}$ contents showed higher removal activity of refractory sulfur compounds.

Figure 12 shows distillation profiles of the product oils. They were similar over all combinations of NMASA-2 series catalysts, suggesting that the cracking reaction occurred to the same extent over each catalyst, even though HDS and hydrogenation activities were different. Figure 13 shows the densities of the product oils. NMASA-2(27) resulted in the lowest product density among the NMASA series of catalysts. Its highest hydrogenation activity was confirmed by the lowest density.

The ratio of alumina to silica was optimized at $27-30 \%$ silica, which was lower than that reported for the cracking catalyst in which alumina was the minor component [21]. The alumina surface is thought to anchor NiMoS by the surrounding silica particles, enhancing the acidity of alumina, as reported for fluid catalytic cracking (FCC) catalysts [22]. The alumina crystal size must be optimized for dispersion of NiMoS on its surface without interference from the silica surface. The acidity of alumina must be induced through contact with silica. A larger amount of silica surrounding smaller alumina particles induces greater acidity; thus, the former and latter roles of alumina can be optimized by the size of the alumina crystals [23, 24].

The acidity of alumina for deep HDS accelerates HDS of refractory sulfur species through extensive hydrogenation of at least one phenyl ring in the dibenzothiophene ring, which relaxes the steric hindrance of 4,6-dialkyl dibenzothiophenes [25]. Several theories have been proposed to explain how the acidity of the support enhances hydrogenation, including proton transfer to the hydrogenation site on NiMoS, strong 
adsorption of the aromatic ring in the acidic site neighboring the hydrogenation site, and induced acidity of NiMoS; however, none of these theories has been confirmed [26].

3.4 Effects of $\mathrm{H}_{2}$ pressure and LHSV on catalytic activity of LX6/NMASA-2(27)

Figure 14 shows sulfur content in HDS oil over LX6/NMASA-2(27) and LX6 alone under $\mathrm{H}_{2}$ pressures from 2.5 to $7.5 \mathrm{MPa}$ at $320-370^{\circ} \mathrm{C}$. LX6 and its combination with NMASA-2(27) showed similar activities under a $\mathrm{H}_{2}$ pressure of $2.5 \mathrm{MPa}$, whereas LX6/NMASA-2(27) showed much higher activity at 5.0 MPa compared with that of LX6 alone. Increased $\mathrm{H}_{2}$ pressure (7.0 MPa) increased the activity of LX6/NMASA2(27) slightly but did not significantly affect that of LX6 alone. Thus, NMASA-2(27) is an excellent hydrogen-active catalyst that favors $\mathrm{H}_{2}$ pressures beyond $5 \mathrm{MPa}$.

Figure 15 shows the effects of LHSV on HDS activity over LX6, LX6/NMASA-2(27), and NMASA2(27). The rate constant was calculated by adjusting the reaction order to fit the linear relationship. The reaction order of LX6 alone was higher than those of LX6/NMASA-2(27) and NMASA-2(27), whereas the reaction order of NMASA-2(27) was close to 1.0. Thus, HDS progress for reactive and refractory sulfur species was governed by first-order reaction kinetics over NMASA-2(27), which removed refectory sulfur species more effectively by the end of the reaction. In contrast, HDS of refractory sulfur species was different over LX6. NMASA-2(27) showed higher acidity than LX6, and the acidity of this support can accelerate HDS of refractory sulfur species through extensive hydrogenation of one phenyl ring.

\subsection{Life stability of the catalysts}

Figure 16 shows the life stability of NMASA-2(27) in a single bed and LX6/NMASA-2(27) in a double bed where the reaction temperature was adjusted to achieve a constant $8 \mathrm{ppm} \mathrm{S}$ for the HDS oil. The activity of NMASA-2(27) decreased for the first $1000 \mathrm{~h}$, and the reaction temperature was increased from 
350 to $355^{\circ} \mathrm{C}$ to achieve the desired $8 \mathrm{ppm} \mathrm{S}$ in the product. Deactivation was observed during the initial period, and the reaction temperature was factored at 340 and $355^{\circ} \mathrm{C}$ from $1000 \mathrm{~h}$ to $3500 \mathrm{~h}$.

In contrast, LX6/NMASA-2(27) in a double bed was heated at $\sim 355^{\circ} \mathrm{C}$ up to $4500 \mathrm{~h}$ to achieve $8 \mathrm{ppm} \mathrm{S}$. The stable activity was obtained by combining two catalysts in the dual-layer bed. Such stable activity is favorable for commercial refineries.

\section{Conclusions}

The flow reactor with a dual-layer catalyst bed using an optimized alumina-silica-supported NM catalyst in the second bed for deep HDS of SRGO achieved the regulated level of sulfur. This process is more favorable for product distributions of distillation and density, as well as sufficient life stability for long-term operation.

HDS activities were investigated using the dual-layer catalyst bed where the first-layer catalyst was LX6 and the second-layer catalysts varied. The combination of LX6 and NMASA-2 was much more active than the other four combinations, achieving 6.6 and $2 \mathrm{ppm} \mathrm{S}$ at 345 and $360^{\circ} \mathrm{C}$, respectively. Figure 4 suggests that half the NMASA-2 could be replaced by LX6 to achieve far less than $10 \mathrm{ppm}$ S at both 345 and $360^{\circ} \mathrm{C}$. Such activities are favorable for long-term operation because deactivation of the catalysts towards the end of a run requires higher reaction temperatures to compensate for the activity loss. LX6 and NMASA-2 shared their respective roles for rapid HDS of reactive and refractory sulfur species, respectively. Among ASAs with similar silica content of 24-28\%, ASA2-27 was the best support for the second-layer catalyst. ASA3-24 was slightly inferior to ASA 2-27 for HDS performance. ASA1-28 was inferior to ASA 2-27 and ASA3-24. The major difference between these supports was their alumina crystal size, in the order of ASA $1>$ ASA $2>$ ASA 3. Thus, the largest alumina crystal size corresponded to the worst performance, and the intermediate size was better than the smallest size.

ASA2-27 had an optimized morphology due to the surrounding silica and the proper alumina crystal size; thus, it was the best support for the second-layer catalyst. Dispersion and arrangement of nanoparticles 
in the alumina/silica oxide composites were important factors governing the HDS reaction. Optimized distribution of nanoscale alumina crystalline particles on the surface of silica is an effective method for increasing HDS through enhanced hydrogenation activity of catalysts.

\section{References}

[1] A. Marafi, A. Al-Hindi,A. Stanislaus, Deep desulfurization of full range and low boiling diesel streams from Kuwait Lower Fars heavy crude, Fuel Processing Technology 88 (2007) 905-911.

[2] C. Song,X. Ma, New design approaches to ultra-clean diesel fuels by deep desulfurization and deep dearomatization, Applied Catalysis B: Environmental 41 (2003) 207-238.

[3] T.C. Ho, Deep HDS of diesel fuel: chemistry and catalysis, Catalysis Today 98 (2004) 3-18.

[4] N. Kunisada, K.-H. Choi, Y. Korai, I. Mochida,K. Nakano, Contrast activities of four alumina and aluminasilica-supported nickel-molybdenum sulfide catalysts for deep desulfurization of gas oils, Applied Catalysis A: General 279 (2005) 235-239.

[5] R. Shafi,G.J. Hutchings, Hydrodesulfurization of hindered dibenzothiophenes: an overview, Catalysis Today 59 (2000) 423-442.

[6] X. Li, A. Wang, M. Egorova,R. Prins, Kinetics of the HDS of 4,6-dimethyldibenzothiophene and its hydrogenated intermediates over sulfided Mo and NiMo on [gamma]- $\mathrm{Al}_{2} \mathrm{O}_{3}$, Journal of Catalysis 250 (2007) 283-293.

[7] S. Zeng, J. Blanchard, M. Breysse, Y. Shi, X. Su, H. Nie, et al., Mesoporous materials from zeolite seeds as supports for nickel-tungsten sulfide active phases: Part 2. Catalytic properties for deep hydrodesulfurization reactions, Applied Catalysis A: General 298 (2006) 88-93.

[8] T. Klimova, J. Reyes, O. Gutiérrez,L. Lizama, Novel bifunctional NiMo/Al-SBA-15 catalysts for deep hydrodesulfurization: effect of support Si/Al ratio, Applied Catalysis A: General 335 (2008) 159-171.

[9] N. Kunisada, K.-H. Choi, Y. Korai,I. Mochida, Effective supports to moderate $\mathrm{H}_{2} \mathrm{~S}$ inhibition on cobalt and nickel molybdenum sulfide catalysts in deep desulfurization of gas oil, Applied Catalysis A: General 260 (2004) 185-190.

[10] L. Ding, Y. Zheng, Z. Zhang, Z. Ring,J. Chen, HDS, HDN, HDA, and hydrocracking of model compounds over Mo-Ni catalysts with various acidities, Applied Catalysis A: General 319 (2007) 25-37.

[11] S.D. Sumbogo Murti, H. Yang, K.-H. Choi, Y. Korai,I. Mochida, Influences of nitrogen species on the 
hydrodesulfurization reactivity of a gas oil over sulfide catalysts of variable activity, Applied Catalysis A: General 252 (2003) 331-346.

[12] N. Kagami, B.M. Vogelaar, A.D.v. Langeveld,J.A. Moulijn, Reaction pathways on $\mathrm{NiMo} / \mathrm{Al}_{2} \mathrm{O}_{3}$ catalysts for hydrodesulfurization of diesel fuel, Applied Catalysis A: General 293 (2005) 11-23.

[13] V. Sundaramurthy, A.K. Dalai,J. Adjaye, Effect of phosphorus addition on the hydrotreating activity of $\mathrm{NiMo} / \mathrm{Al}_{2} \mathrm{O}_{3}$ carbide catalyst, Catalysis Today 125 (2007) 239-247.

[14] E. Lecrenay, K. Sakanishi, I. Mochida,T. Suzuka, Hydrodesulfurization activity of CoMo and NiMo catalysts supported on some acidic binary oxides, Applied Catalysis A: General 175 (1998) 237-243.

[15] S.K. Maity, J. Ancheyta, L. Soberanis,F. Alonso, Alumina-silica binary mixed oxide used as support of catalysts for hydrotreating of Maya heavy crude, Applied Catalysis A: General 250 (2003) 231-238.

[16] W. Daniell, U. Schubert, R. Glockler, A. Meyer, K. Noweck,H. Knozinger, Enhanced surface acidity in mixed alumina-silicas: a low-temperature FTIR study, Applied Catalysis A: General 196 (2000) 247-260.

[17] N. Kunisada, K.-H. Choi, Y. Korai, I. Mochida,K. Nakano, Optimization of silica content in alumina-silica support for NiMo sulfide to achieve deep desulfurization of gas oil, Applied Catalysis A: General 273 (2004) $287-294$.

[18] S. Shin, H. Yang, K. Sakanishi, I. Mochida, D.A. Grudoski,J.H. Shinn, Inhibition and deactivation in staged hydrodenitrogenation and hydrodesulfurization of medium cycle oil over $\mathrm{NiMoS} / \mathrm{Al}_{2} \mathrm{O}_{3}$ catalyst, Applied Catalysis A: General 205 (2001) 101-108.

[19] R. Marinkovic-Neducin, E. Kis, M. Djuric, J. Kiurski, D. Obadovic, P. Pavlovic, R. Micic, B.D.G.F.Froment, P. Grange, Studies in Surface Science and Catalysis 106 (1997) 307-310.

[20] H.S. Cerqueira, G. Caeiro, L. Costa,F. Ramôa Ribeiro, Deactivation of FCC catalysts, Journal of Molecular Catalysis A: Chemical 292 (2008) 1-13.

[21] W.W. Pang, Y.Z. Zhang, K.H. Choi, J.K. Lee, S.H. Yoon, I. Mochida, et al., Design of catalyst support for deep hydrodesulfurization of gas oil, Petroleum Science and Technology 27 (2009) 1349 -1359.

[22] J. Scherzer, Designing FCC catalysts with high-silica Y zeolites, Applied Catalysis 75 (1991) 1-32.

[23] R. Navarro, B. Pawelec, J.L.G. Fierro,P.T. Vasudevan, Dibenzothiophene hydrodesulfurization on silicaalumina-supported transition metal sulfide catalysts, Applied Catalysis A: General 148 (1996) 23-40.

[24] A. Germain, T. Akouz,F. Figueras, Vapour-phase nitration of fluorobenzene with N2O4 over aluminosilicates: effects of structure and acidity of the catalyst, Applied Catalysis A: General 136 (1996) 57-68. 
[25] T. Isoda, S. Nagao, X. Ma, Y. Korai,I. Mochida, Catalytic activities of NiMo and $\mathrm{CoMo} / \mathrm{Al}_{2} \mathrm{O}_{3}$ of variable $\mathrm{Ni}$ and Co contents for the hydrodesulfurization of 4,6-dimethyldibenzothiophene in the presence of naphthalene, Applied Catalysis A: General 150 (1997) 1-11.

[26] M. Vrinat, D. Hamon, M. Breysse, B. Durand,T. des Courieres, Zirconia- and alumina-supported molybdenum-based catalysts: a comparative study in hydrodesulfurization and hydrogenation reactions, Catalysis Today 20 (1994) 273-282. 


\section{Table captions}

Table 1. Surface area, pore volume and pore size of ASA supports

\begin{tabular}{lccc}
\hline Support & $\begin{array}{c}\text { Surface area } \\
\left(\mathrm{m}^{2} / \mathrm{g}\right)\end{array}$ & $\begin{array}{c}\text { Pore size } \\
(\mathrm{nm})\end{array}$ & $\begin{array}{c}\text { Pore volume } \\
\left(\mathrm{cm}^{3} / \mathrm{g}\right)\end{array}$ \\
\hline ASA1-28 & 335 & 3.1 & 0.69 \\
ASA2-27 & 339 & 2.7 & 0.70 \\
ASA3-24 & 303 & 2.1 & 0.58 \\
\hline
\end{tabular}

Table 2. Standard reaction conditions

\begin{tabular}{lllll}
\hline Operation conditions & & Feed properties & SRGO1 & SRGO2 \\
\hline LHSV $\left(\mathrm{hr}^{-1}\right)$ & 1.0 & Density & 0.85 & 0.86 \\
$\mathrm{H}_{2} / \mathrm{Oil}\left(\mathrm{Nm}^{3} / \mathrm{kl}\right)$ & 250 & Sulfur & 1.17 & 1.54 \\
$\mathrm{ppH}_{2}(\mathrm{MPa})$ & 5.0 & Nitrogen & 155 & 130 \\
\hline
\end{tabular}




\section{Figure captions}

Fig. 1. Pore size distributions of ASA supports, measured by the BJH desorption procedure.

Fig. 2. TEM images of ASA1-28, ASA2-27, and ASA3-24.

Fig. 3. Catalytic activity observed in the single-layer catalyst bed (Feed SRGO2).

Fig. 4. Catalytic activity observed in the dual-layer catalyst bed (Feed SRGO2).

Fig. 5. S GC-AED of HDS products over dual-layer catalyst beds (Feed SRGO2).

Fig. 6. Distillation profiles of HDS products over dual-layer catalyst beds at $345^{\circ} \mathrm{C}$ (Feed SRGO2).

Fig. 7. Densities of HDS products over dual-layer catalyst beds (Feed SRGO2).

Fig. 8. Carbon GC-AED of HDS products over dual-layer catalyst beds (Feed SRGO2).

Fig. 9. Aromatic content over dual-layer catalyst beds (Feed SRGO2).

Fig. 10. HDS activity over LX6 and NMASA-2(n) with various $\mathrm{SiO}_{2}$ content (Feed SRGO1).

Fig. 11. S GC-AED of HDS product oils over LX6/NMASA-2(n) series catalysts (Feed SRGO1).

Fig. 12. Distillation curves of product oils over LX6/NMASA-2(n) series catalysts (Feed SRGO1).

Fig. 13. Density of product oils over LX6/NMASA-2(n) series catalysts (Feed SRGO1).

Fig. 14. Effect of $\mathrm{H}_{2}$ pressure over LX6/NMASA-2(27) and LX6 alone (Feed SRGO2).

Fig. 15. Reaction kinetics over LX6, NMASA-2(27), and LX6/NMASA-2(27) (Feed SRGO2).

Fig. 16. Life stability tests of LX6/NMASA-2(27) and NMASA-2(27).

Normalized conditions

LHSV: $1.0 \mathrm{~h}^{-1}$

Feed SRGO2 S: $15,400 \mathrm{ppm}$

Product S: 8 ppm

Reaction order: 1.1 


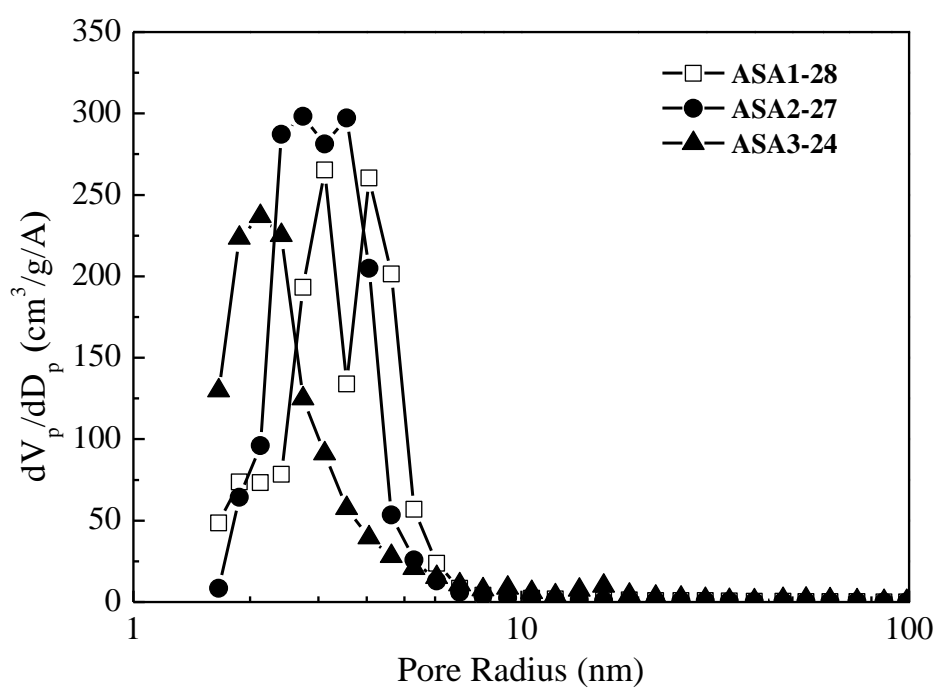

Fig.1. Pore size distribution of ASA supports measured by BJH desorption procedure.
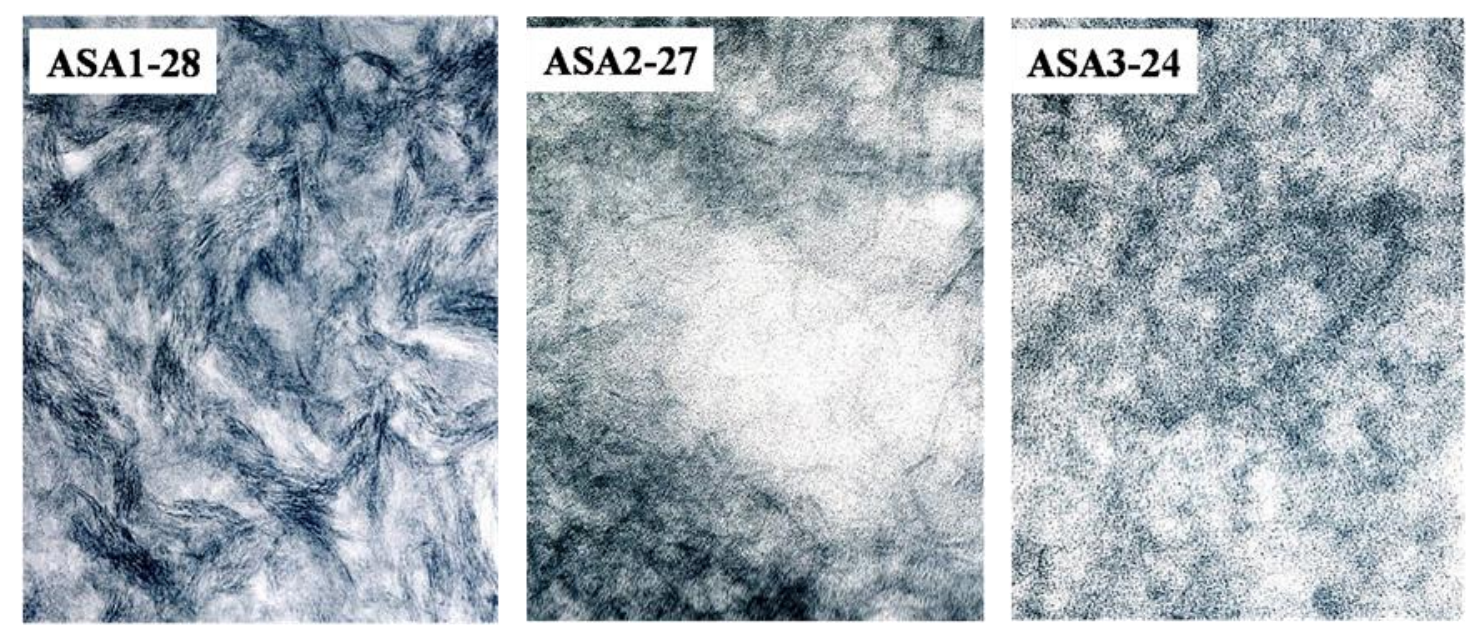

Fig. 2. TEM images of ASA1-28, ASA2-27, and ASA3-24. 


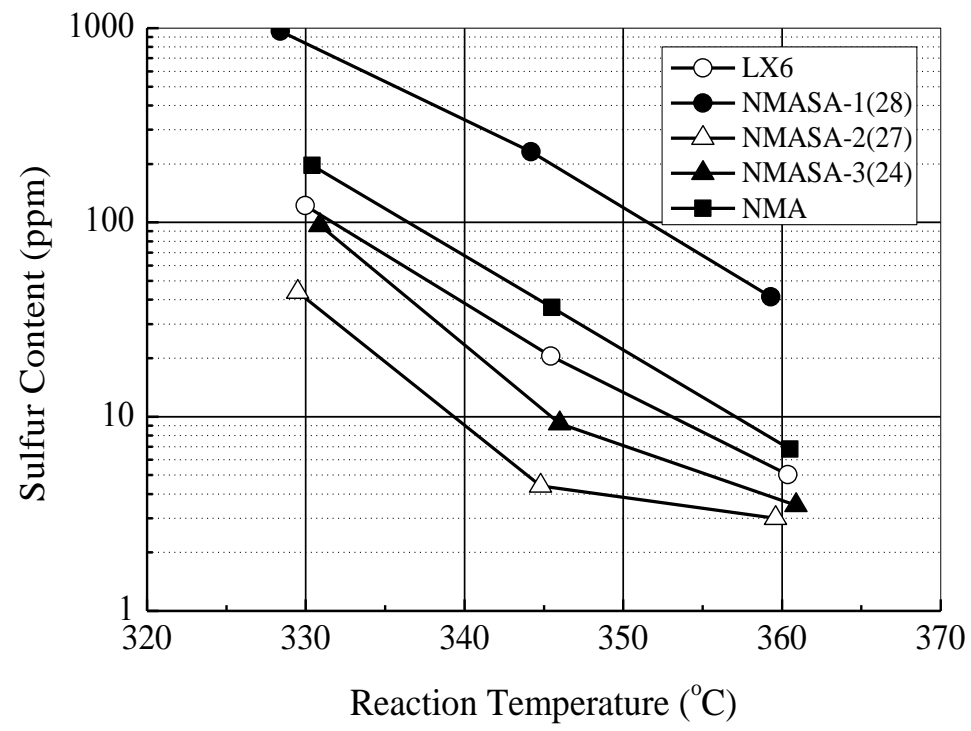

Fig.3. Catalytic activity observed in single layer catalyst bed. (Feed SRGO2)

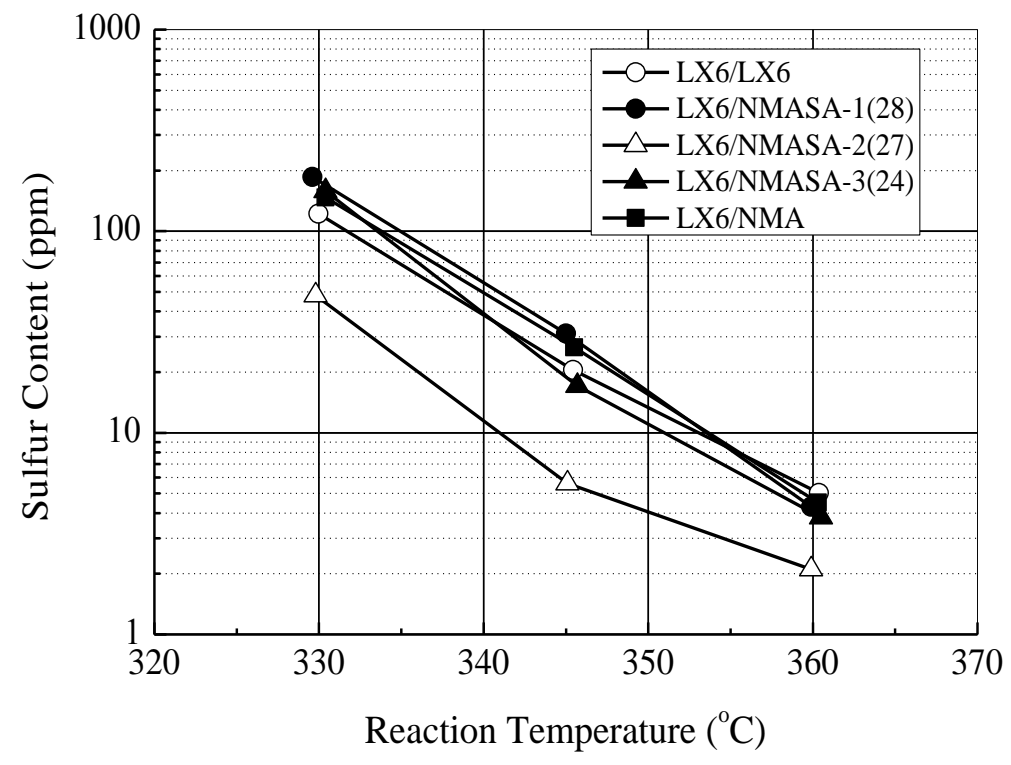

Fig.4. Catalytic activity observed in dual layers catalyst bed. (Feed SRGO2) 


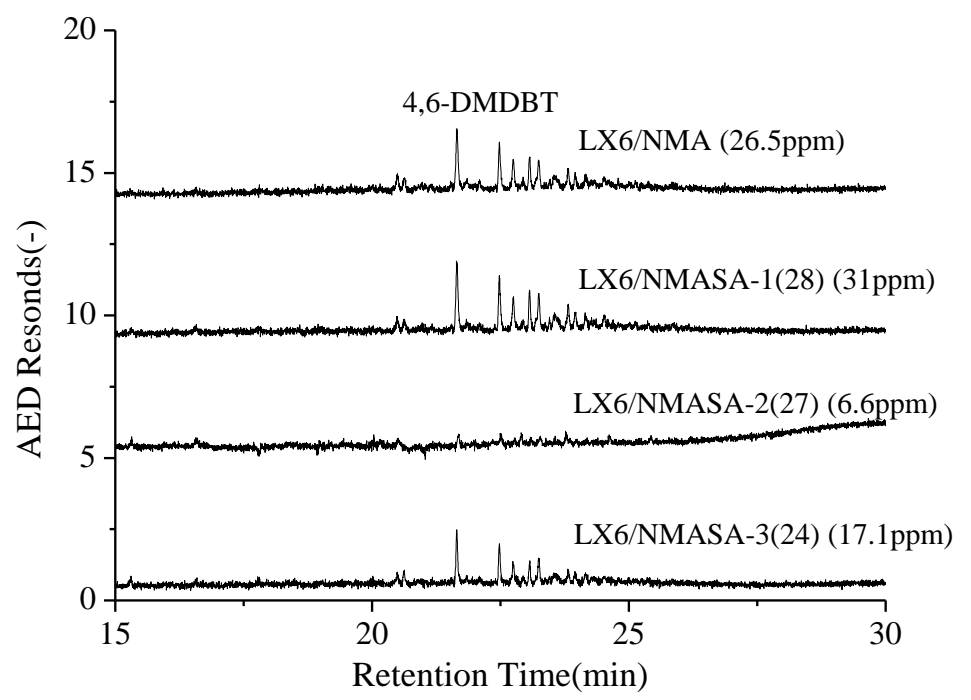

Fig.5. S GC-AED of HDS product over dual layers catalyst beds. (Feed SRGO2)

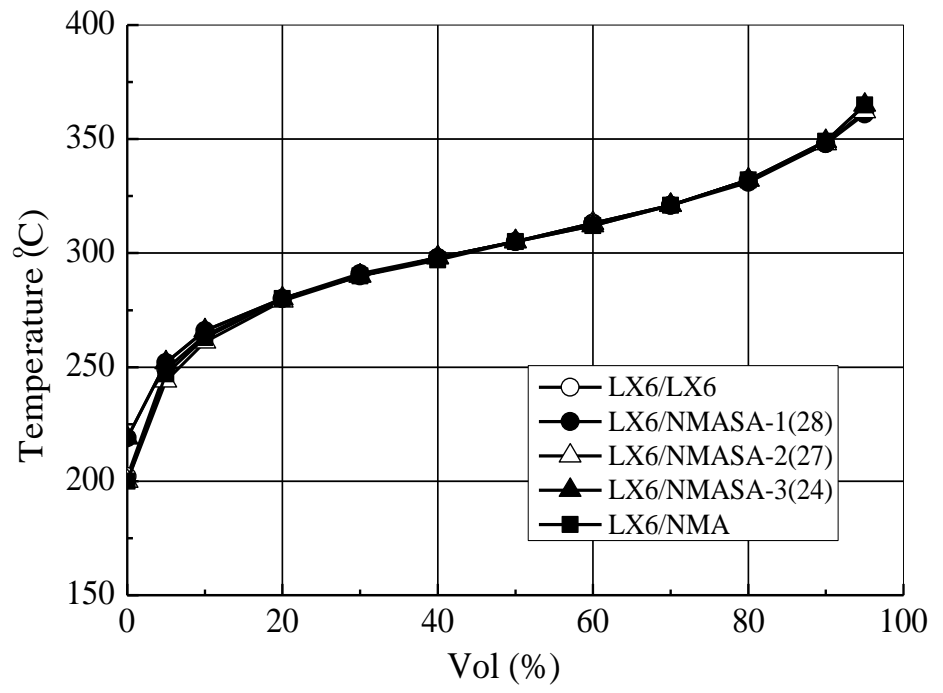

Fig.6. Distillation profiles of the HDS products. (Feed SRGO2) 


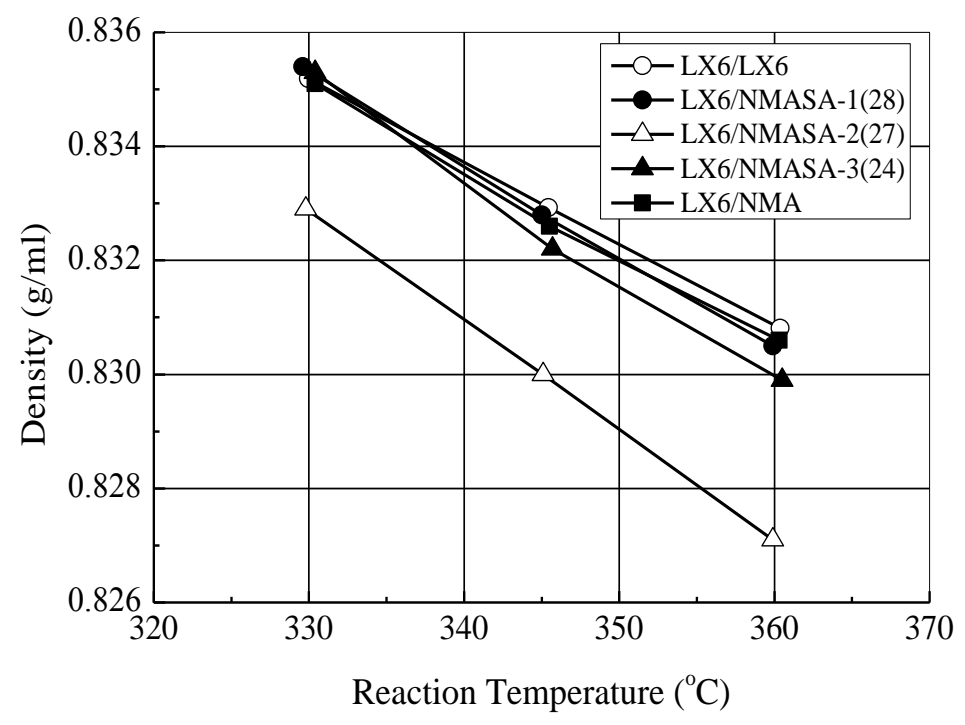

Fig.7. Density of the HDS products. (Feed SRGO2)

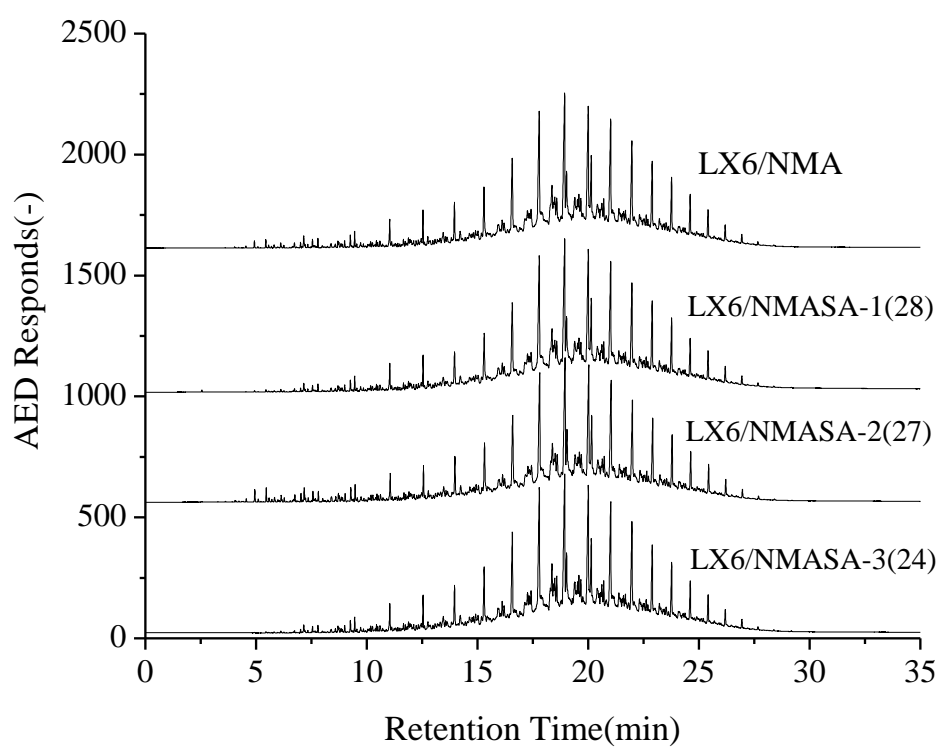

Fig.8. Carbon GC-AED of the HDS products. (Feed SRGO2) 


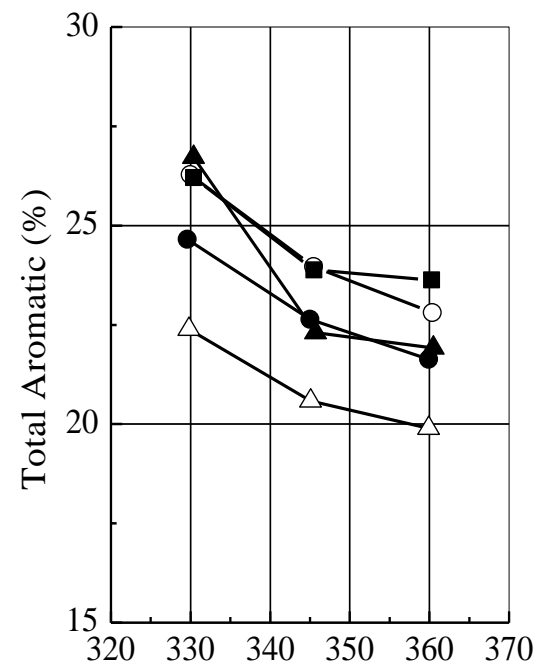

Reaction Temperature $\left({ }^{\circ} \mathrm{C}\right)$

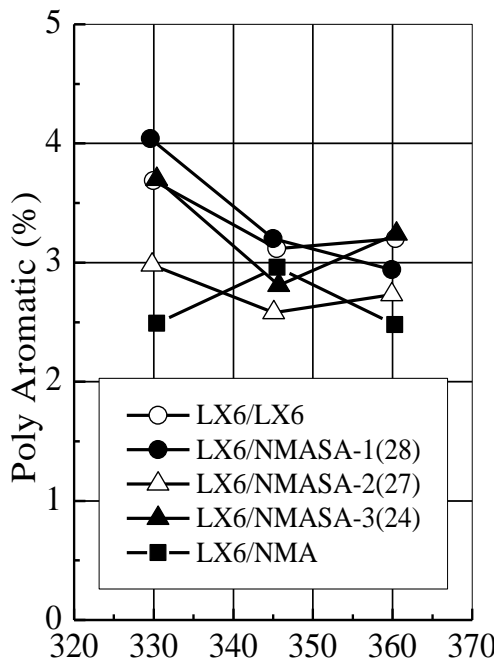

Reaction Temperature $\left({ }^{\circ} \mathrm{C}\right)$

Fig.9. Aromatic contents. (Feed SRGO2)

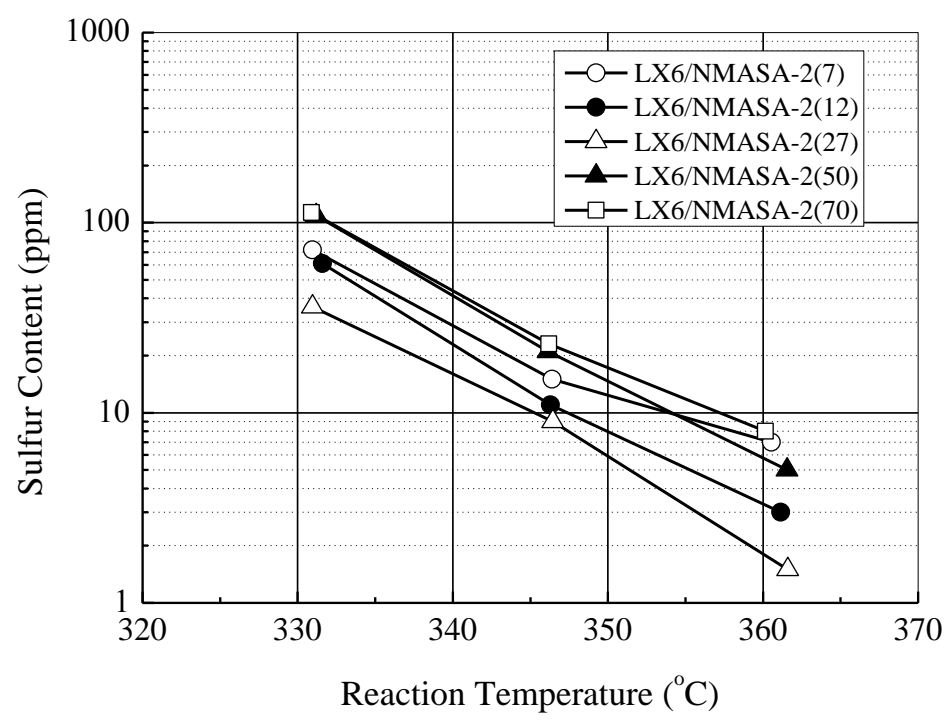

Fig.10. HDS activity over LX6 and NMASA-2(n) with various $\mathrm{SiO}_{2}$ content. (Feed SRGO1) 


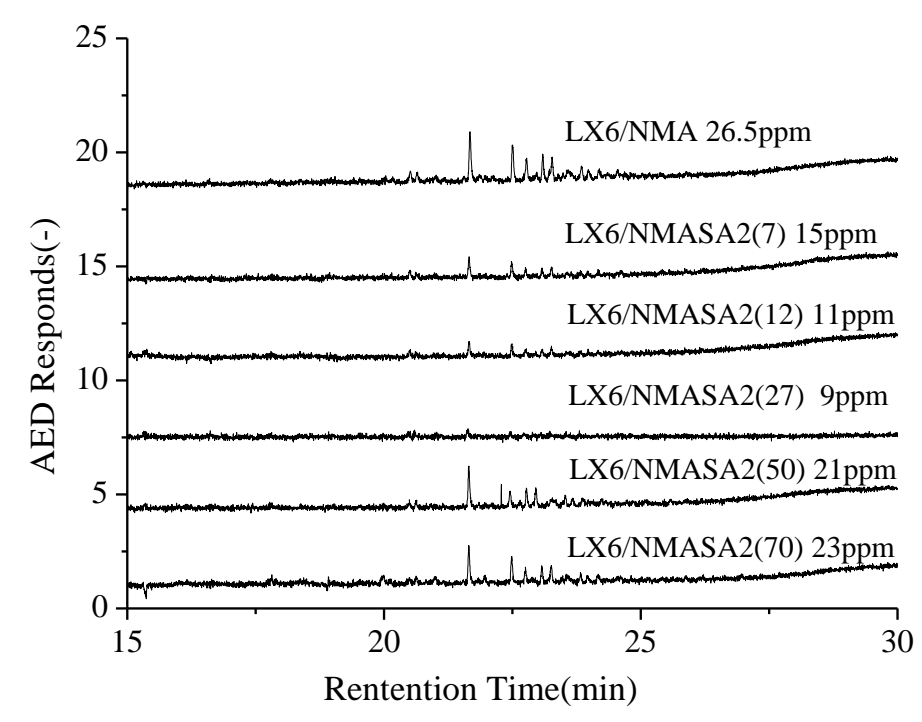

Fig.11. Sulfur GC-AED of the HDS product oils over LX6/NMASA-2(n) series catalysts. (Feed SRGO1)

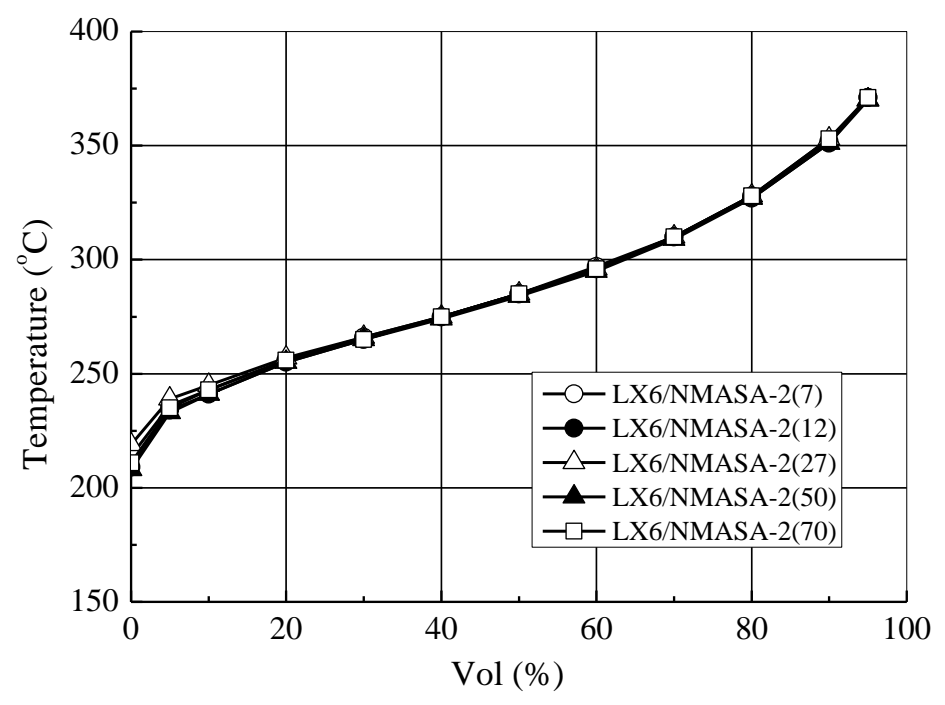

Fig.12. Distillation curve of product oils over LX6/NMASA-2(n) series catalysts. (Feed SRGO1) 


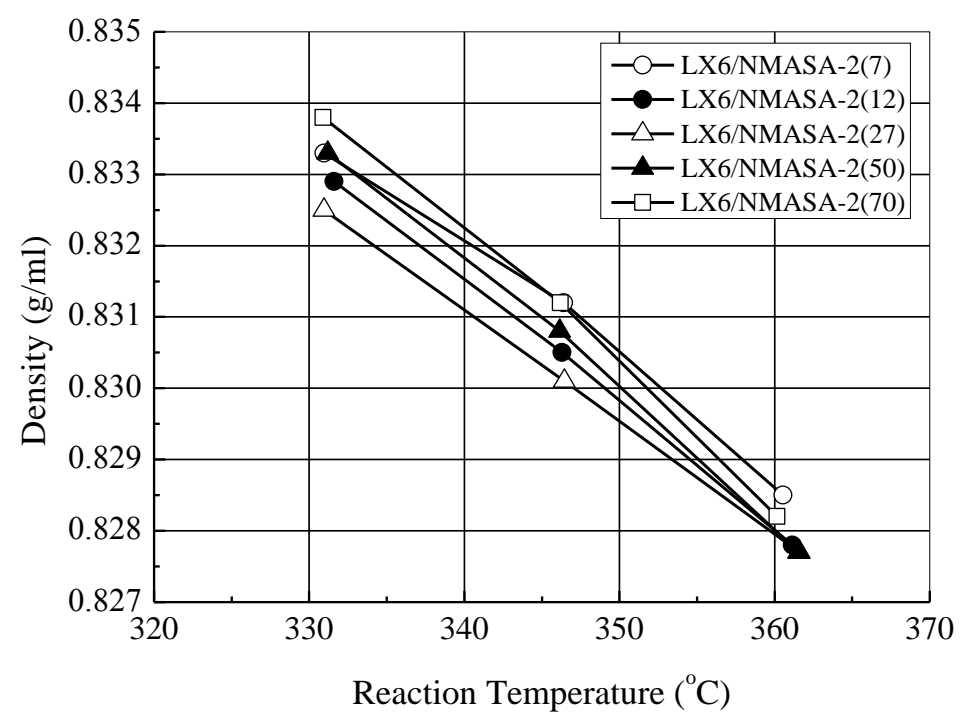

Fig.13. Density of product oil over LX6/NMASA-2(n) series catalysts. (Feed SRGO1)

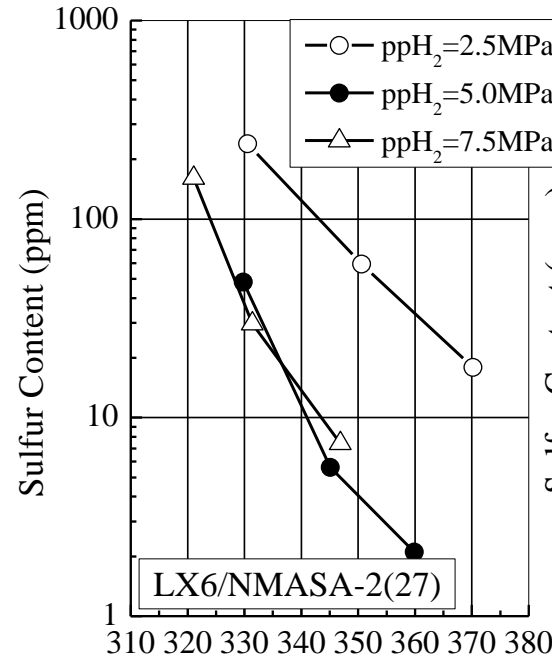

Reaction Temperature $\left({ }^{\circ} \mathrm{C}\right)$

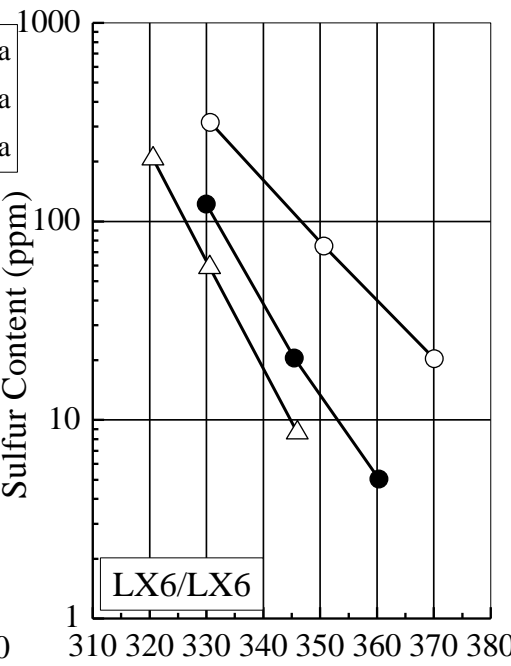

Reaction Temperature $\left({ }^{\circ} \mathrm{C}\right)$

Fig.14. Effects of hydrogen pressure over LX6/NMASA-2(27) and LX6 alone. (Feed SRGO2) 


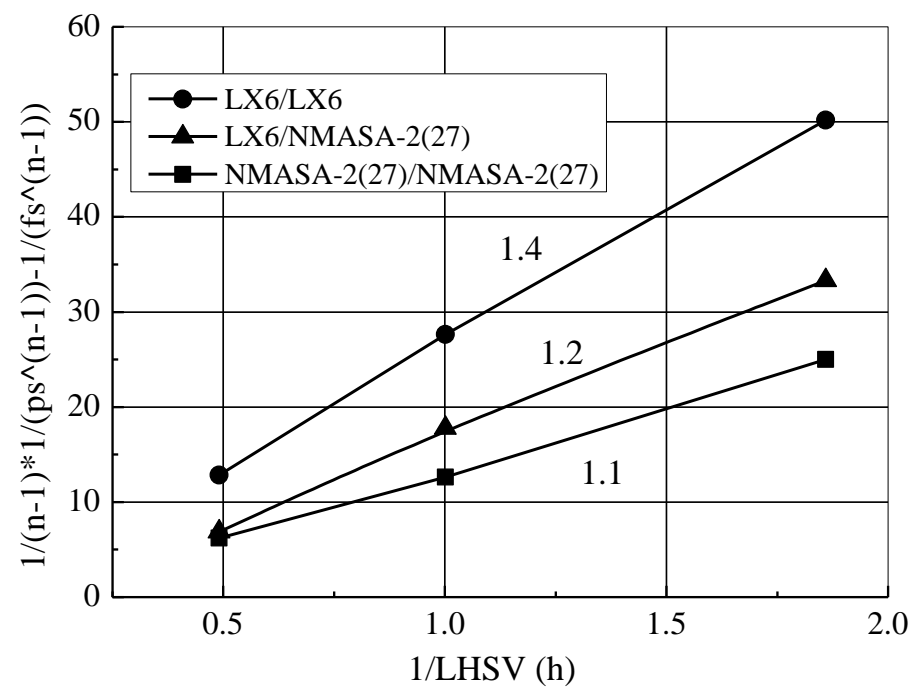

Fig.15. Kinetics over LX6, NMASA-2(27) alone and their combination. (Feed SRGO2)

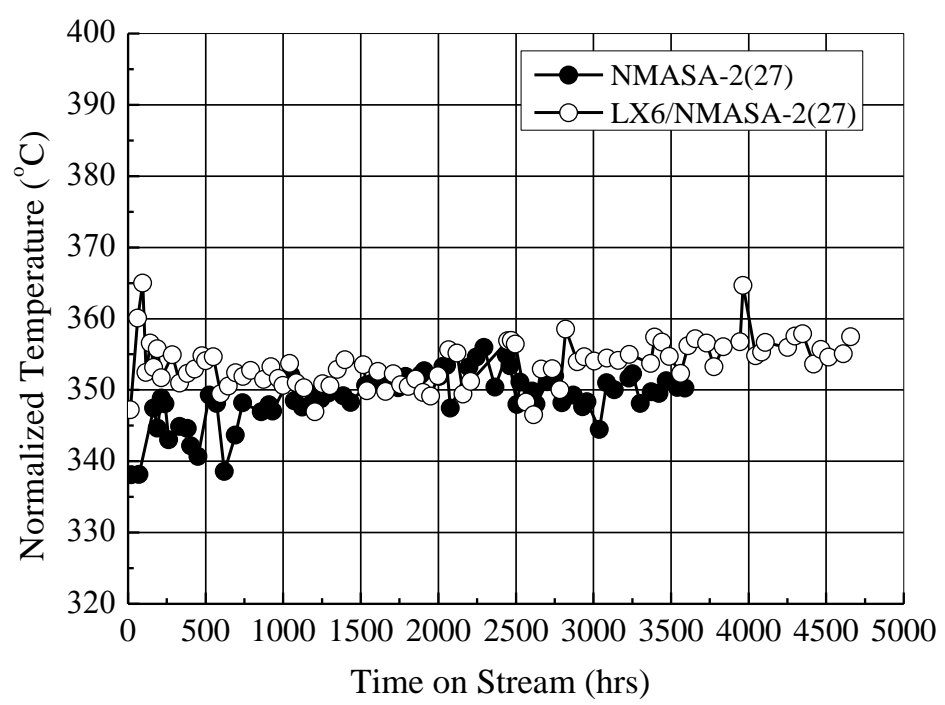

Fig.16. Life stability test of LX6/NMASA-2(27) and NMASA-2(27) alone.

Normalized conditions

LHSV $1.0 \mathrm{hr}-1$

Feed SRGO2 S 15400ppm

Product S 8ppm

Reaction order 1.1 